\title{
A GESTÃO DO IMPONDERÁVEL E A ESPERANÇA: NOTAS EXPLORATÓRIAS SOBRE CONHECIMENTO \\ E ESCOLA ENTRE QUEBRADEIRAS DE COCO
}

\section{THE MANAGEMENT OF THE IMPONDERABLE AND THE HOPE: EXPLORATORY NOTES ABOUT KNOWLEDGE AND SCHOOL AMONG COCONUT BREAKERS}

\author{
Martina Ahlert*
}

\section{Introdução}

A quebra do coco babaçu é uma atividade extrativista presente, principalmente, nos estados do Tocantins, Piauí, Maranhão e Pará, localizados no Norte e Nordeste do Brasil. É realizada majoritariamente por mulheres, que encontram ali uma fonte de recurso financeiro. Estima-se que existam mais de trezentas mil mulheres quebradeiras de coco babaçu ${ }^{1}$ nessa região do país. Do coco se utilizam a amêndoa (parte de maior valor no mercado), o mesocarpo e o endocarpo para a produção de azeite, farinha, sabão, cosméticos, carvão e energia.
Durante o ano de 2011 participei de uma pesquisa de campo ${ }^{2}$ com algumas mulheres quebradeiras de coco babaçu em Codó. Localizado na região leste do Maranhão, na região dos Cocais, o município possui cerca de 120 mil habitantes (IBGE, 2010) ${ }^{3}$ e se encontra distante trezentos quilômetros da capital do estado, São Luís. Grande parte da população de Codó se dedica às atividades realizadas no meio rural, como a quebra do coco e a plantação de gêneros alimentícios. 0 campo é central como espaço de trabalho, ainda que muitas pessoas que nele desempenham atividades laborais não possuam terras de sua propriedade,

*Doutora em Antropologia Social pela Universidade de Brasília, professora do Departamento de Sociologia e Antropologia da Universidade Federal do Maranhão (DESOC/UFMA /São Luís/MA/Brasil). ahlertmartina@gmail.com.

1. Dados do Movimento Interestadual das Quebradeiras de Coco Babaçu (MIQCB).

2. Agradeço, imensamente, a Joana Etiene Lima Silva, que chamou nossa atenção para o tema da escola entre as quebradeiras de coco. Igualmente, agradeço as contribuições generosas dos pareceristas do texto. 3. Dados do Instituto Brasileiro de Geografia e Estatística (IBGE), disponiveis em www.ibge.com.br. 
plantando em áreas emprestadas ou alugadas. As mulheres com as quais convivi por intermédio da pesquisa eram moradoras da zona urbana de Codó, mas se deslocavam para espaços da zona rural para a coleta e quebra do coco.

Neste artigo, discorro sobre a relação entre o conhecimento tradicional da quebra de coco - aprendido pelas mulheres de Codó normalmente na infância, a partir da ação de outras mulheres -, e o conhecimento escolar transmitido por intermédio das instituições do Estado (as escolas). As quebradeiras de coco babaçu, ao falarem sobre as aproximações e distanciamentos entre essas formas de transmissão de saberes, também relatavam suas impressões sobre a passagem do tempo - medido, especialmente, por uma análise de suas próprias trajetórias em comparação às experiências de vida de seus/suas filhos(as) e netos(as). Elas pontuavam, por um lado, que o futuro era um tempo que demandava novas qualificações e conhecimentos, o que tornava a ida à escola, entre as novas gerações, algo fundamental; por outro lado, era também o tempo do imponderável e do incerto, diante do qual era preciso garantir o que era sentido como próximo e que fora a segurança das suas famílias, do ponto de vista econômico - a quebra de coco.

A pesquisa base deste artigo iniciou com a escrita de um projeto submetido a um edital do Ministério do Desenvolvimento
Social (MDS) em parceira com o Ministério de Ciência e Tecnologia (MCT) e o Conselho Nacional de Desenvolvimento Científico e Tecnológico (CNPq), em 20104. 0 tema articulador dos eixos temáticos do edital eram as questões relativas ao enfrentamento da fome e ao combate à pobreza - assuntos caros ao governo federal naquele momento. Uma professora do Instituto Federal de Educação, Ciência e Tecnologia do Maranhão (IFMA/Campus Codó) e eu escrevemos um projeto para investigar os impactos do recebimento do benefício do Programa Bolsa Família $^{5}$ entre quebradeiras de coco babaçu da cidade. Na execução da pesquisa contamos com a participação de alguns bolsistas: cinco alunos e alunas da graduação dos cursos de química e ciências agrárias do IFMA; duas professoras de redes municipais de ensino e uma mestra em antropologia social.

Optamos, naquele contexto, por iniciar nosso trabalho a partir de duas associações de quebradeiras de coco localizadas no perímetro urbano de Codó. Cada uma tinha cerca de trezentas mulheres inscritas como sócias (e entre elas alguns homens), e apenas cerca de um quarto desse contingente frequentava assiduamente as reuniões. Para conhecer as quebradeiras, utilizamos diferentes técnicas de pesquisa. Em um primeiro momento realizamos um questionário ${ }^{6}$ para construir um perfil daquelas que participavam das atividades das associações.

4. 0 projeto se intitulou "Estratégias de enfrentamento da fome e construções de gênero: o cotidiano das quebradeiras de coco babaçu na Região dos Cocais” (Edital MDS/CNPq/MCT 036/2010). A equipe foi formada por Erika Albuquerque, Tatiane Duarte, Marineide Ferreira, Joana Etiene Lima Silva, Eliana Silva Teles, Khety Elane de Oliveira, Atalício Gomes de Sousa Moreira, Anderson Bezerra e Emanuelly Karoline de Souza. 5. 0 Programa Bolsa Família é um programa social do governo federal, que tem como base a transferência direta e condicionada de renda. Os valores de repasse, em fevereiro de 2015, estavam entre 77 e 336 reais mensais. Para uma família receber o benefício, sua renda deveria ser de até 154 reais per capita. 6. Os questionários foram aplicados com cem mulheres, cinquenta em cada associação de quebradeiras de coco. 0 preenchimento foi realizado em reuniões e outros eventos, nas sedes dos grupos. 
Posteriormente escolhemos doze mulheres para estabelecer maior contato, quando passamos a frequentar suas casas, a acompanhá-las no repasse de alimentos feito por algumas instituições, na ida a serviços públicos municipais de assistência social, nas atividades associativas, tais como as reuniões, os bingos e almoços promocionais. Com cada uma delas fomos conhecer a atividade da quebra de coco, tanto no interior do município como em depósitos do fruto na cidade. Depois de algum tempo de convivência, realizamos, em suas casas, uma entrevista com roteiro semiestruturado.

Cada uma das técnicas de pesquisa empregada apresentou particularidades. Os momentos que envolviam instrumentos escritos como, por exemplo, a aplicação de questionários e o uso de consentimentos informados, foram percebidos pela equipe como desconfortáveis, haja vista a baixa escolaridade de muitas das quebradeiras e, consequentemente a imposição de algo que não lhes era familiar. Nesses dois momentos, conversamos individualmente com cada uma delas, realizando a leitura dos textos - medida que, sabemos, supriu muito parcialmente as dificuldades encontradas e não extinguiu (quiçá tenha minimizado) o caráter assimétrico da relação de pesquisa.

Para além do uso de diferentes técnicas de investigação, estivemos inspirados pela etnografia, preocupação teórico-metodológica que é central para a antropologia e que coloca a observação, a convivência e interação como fontes de conhecimento (FONSECA, 1999; PEIRANO, 2014; CALÁVIA-SAEZ, 2013; WAGNER, 2010; STRATHERN, 2006). 0 material, construído em campo, nos ajudou a ver como se dá “o contínuo processo de encontrar sentido no mundo das pessoas" (TOREN, 2010, p. 20) e, ao mesmo tempo, nos fez pensar nas apostas de pesquisa que realizamos, assim como nas relações que construímos em campo (WAGNER, 2010). Parte considerável da equipe teve, nessa experiência, seu contato inicial com a pesquisa qualitativa, na medida em que se familiarizava com o ambiente universitário, pois era a primeira geração de suas famílias com acesso ao ensino superior público. Retorno a essas questões metodológicas - que acionam questões sobre o saber escolar e sobre desigualdade social na realidade brasileira - nas considerações finais do texto, após a apresentação dos dados da pesquisa de campo.

Este texto é composto por quatro partes. Inicialmente, apresento um dia típico de quebra de coco, descrevendo a atividade e chamando atenção para alguns aspectos que perpassam variáveis como gênero, família e mobilidade, fundamentais para compreender o contexto que narro. Em um segundo momento, trago questões relacionadas à escola e à quebra de coco na infância das quebradeiras para, sem seguida, destacar como essas questões são retomadas quando elas pensam a vida das crianças e adolescentes - seus/suas filhos(as), netos(as) ou sobrinhos(as), por exemplo. Por fim, busco problematizar elementos da relação entre esses diferentes saberes e as balizas que eles fornecem, problematizando questões sobre a passagem do tempo e as formas de imaginar o que virá.

\section{A quebra de coco babaçu}

0 dia das quebradeiras de coco começava ainda antes do amanhecer. Como a maior parte da atividade extrativista era realizada na zona rural do município, antes das sete horas da manhã as mulheres já saíam de suas casas carregando sacolas com os instrumentos de trabalho: machado 
e um pedaço de pau ou mangueira, para apoiá-lo; sacos de ráfia; outro pedaço de pau para quebrar o coco contra o machado; e um facão para abrir caminho na mata.

As quebradeiras se deslocavam a pé, de bicicleta, de moto, de carro ou com o caminhão da Prefeitura. 0 destino variava, já que existiam locais conhecidos para quebra, para onde iam em grupo, e havia "o interior" de cada pessoa, ou seja, o povoado ou terra de referência de sua família. Quando chegavam perto dos locais de quebra, as mulheres colocavam calças embaixo das saias, para proteger as pernas, mas continuavam de chinelos. Para algumas delas, entrar na mata incluía pedidos de licença, pois o espaço era ocupado por bichos (como as cobras) e pelos encantados, seres mais que humanos que povoavam o mundo e caracterizam algumas práticas religiosas locais (AHLERT, 2013b).

As mulheres caminhavam pela mata com destreza, assim como quebravam o coco sem parecer prestar atenção ao ato, dada a familiaridade com a prática. Eram diferentes os ritmos de desempenho de cada uma delas - algumas eram vistas como habilidosas e rápidas, pois tinham, ao término da atividade, uma maior quantidade de coco quebrado e consequentemente, maior rendimento financeiro. Logo, nem todas eram consideradas exímias - existia gente "sem rumo", "sem coordenação" ou "sem força” para exercer a tarefa. De maneira geral, se entendia que "quebrar coco é que nem andar de bicicleta, a gente nunca esquece" como nos disse uma interlocutora, na reunião de uma das associações.

A atividade na mata começava acompanhando as caieiras deixadas no dia anterior. Caieiras eram os buracos feitos no chão, onde se transformava a casca do babaçu em carvão. Depois de escolher um lugar com sombra para deixar os pertences, iniciava a coleta do fruto. Guardado dentro de sacos, ele era, posteriormente, reunido no local da quebra. Nem todo o coco era interessante às quebradeiras, pois poderia estar velho ou ter larvas em seu interior. Uma palmeira também poderia ser considerada boa ou ruim; as quebradeiras o sabiam olhando, porque, segundo suas palavras, as conheciam.

Quando as sacolas de coleta estavam cheias e pesadas, os cocos eram despejados no chão, no local onde haviam ficado os pertences de cada mulher. Em torno deles a quebradeira se sentava. 0 machado era colocado abaixo do joelho e enquanto uma mão segurava o coco a outra quebrava, com o "porrete", sua casca. Havia cuidado para não prejudicar a amêndoa. Algumas vezes o trabalho era feito ao som de uma música do celular ou de um programa de rádio, acompanhado por conversas ou pelo silêncio.

0 almoço era, normalmente, feito na mata e, tal como em suas casas, as mulheres cozinhavam utilizando o carvão do babaçu. Enquanto estivemos em campo vimos refeições que incluíam feijão, farofa de ovo, carne de gado e de frango. Não eram raros, entretanto, os relatos de que normalmente a alimentação se resumia à farinha com cebola, tomate e coentro. As atividades eram retomadas depois do descanso que seguia o almoço e continuavam até o final da tarde. No retorno para a cidade, era comum passar pela casa de algum comprador de coco - onde se vendia o fruto inteiro ou apenas parte dele. Entre os compradores havia intermediários de pequeno porte (como donos de uma casa de comércio no interior) e grandes empresários. Na época da pesquisa de campo, um dia de trabalho rendia entre seis e dez reais, dependendo do ritmo da quebra.

Autores como Sidney Mintz (2001) e Antonio Cândido (2010) nos lembram que 
as atividades que envolvem alimentação entre elas o plantio, a produção e o consumo - não refletem apenas a natureza utilitária ou uma necessidade fisiológica das pessoas. A coleta e quebra do coco babaçu em Codó, que possibilitam acesso a um recurso financeiro, eram, nessa perspectiva, constituintes da vida doméstica das casas (na feitura e preparo dos alimentos, por intermédio, por exemplo, do azeite e do carvão), expressavam ainda uma identidade laboral e participavam de uma dinâmica familiar específica.

Determinada literatura antropológica sobre experiências de pessoas de baixa renda, de grupos ou classes populares no Brasil (FONSECA, 1995, 2004; SARTI, 1996; DUARTE, 1986; ZALUAR, 1985; CALDEIRA, 1984, 1987), mostra a família como eixo centralizador das relações sociais, como fundamento moral (SARTI, 1996), ou ainda como trama holística, fruto de uma concepção de pessoa que se distancia da ideologia do individualismo moderno (DUARTE, 1986). A complementariedade entre o casal - o homem e a mulher -, o prestígio masculino na figura do provedor e a circulação de crianças aparecem tanto na literatura sobre grupos populares na cidade quanto em contextos de campesinato, nos quais a família emerge como unidade de produção e consumo (HEREDIA, 1979; WOORTMANN, 1995; WOORTMANN, K. 2009; GODOI, 1999, 2009; PAULA ANDRADE, 2007).

De forma semelhante aos apontamentos trazidos por essa literatura, as quebradeiras de coco de Codó, quando falavam sobre o babaçu, se referiam às suas famílias como o elemento que justificava e dignificava seu trabalho - era utilizando a família como argumento que falavam sobre a necessidade de trabalhar. 0 resultado das suas atividades raramente era visto como de uso individual; antes servia para o sustento familiar, de forma que costumavam gastar o dinheiro em comida ou em compras de utensílios domésticos (AHLERT, 2013a). Como veremos na sequência do texto, a família também era marcante nas narrativas sobre a infância, nas quais se destacava a presença feminina na quebra de coco. A própria palmeira é metaforicamente uma "mãe" para as mulheres, pois com ela podem contar sempre (BARBOSA, 2006, 2007; ANTUNES, 2006).

A quebra de coco, portanto, permitia às mulheres contribuírem com suas famílias algo que faziam também quando trabalhavam nas roças consideradas dos seus maridos, ainda que, nesses casos, seu trabalho fosse visto sempre como uma “ajuda”. Uma das vantagens da quebra, diretamente relacionada à centralidade da família, era a liberdade de gerir a própria rotina, diferente de outras formas de trabalho tido como feminino ${ }^{7}$ :

\footnotetext{
Eu acho melhor meu servicinho [na quebra] porque tem dia que eu digo assim: "não, hoje eu não vou não, hoje eu vou cuidar da minha casa”. Aí eu não vou. E a pessoa que trabalha de empregada [doméstica], que chova ou que faça sol, tem que ir [...] Quem manda sou eu, só é eu mesma. É meu dinheirinho mesmo, todo dia eu tenho, é eu quem trabalha... (informação verbal ${ }^{8}$ ).
}

7. Os nomes das interlocutoras utilizados nesse artigo são fictícios. É importante mencionar que a maioria das mulheres que se declarava solteira utilizava esse termo, pois não tinha casado formalmente. 8. Depoimento de Dona Jesus, 49 anos, quebradeira de coco, solteira, mãe e avó - em 15/08/2011. 
Eu primeiro digo assim pra mim, porque no mato assim, eu vou pro mato, aí hoje eu vou pro mato, eu quebro coco até a hora que der vontade. Às vezes, quando não dá vontade, eu venho embora. Aí, nas casas [para trabalhar com serviços domésticos], às vezes a gente tem que ir todo dia (informação verbal ${ }^{9}$ ).

Dona Jesus e Dona Efigênia ${ }^{10}$, nas falas acima transcritas, enfatizaram a possibilidade de escolha dos dias de trabalho, a ausência de um patrão e de regras estabelecidas como vantagens do extrativismo, sublinhando aspectos como liberdade e autonomia. As mulheres que saíam de suas casas para o trabalho na quebra, portanto, trabalhavam pelo que consideravam a razão por excelência, suas famílias. Esses deslocamentos cotidianos, que as afastavam da rotina familiar, já que passavam o dia na mata, também as conectavam às suas famílias. Tais deslocamentos não são, nesse sentido, distantes do que se compreende de outras mobilidades, como as migrações e a circulação de crianças (GODOI, 2009, 2014; MENEZES, 2009; WOORTMANN, 2009), quando homens, mulheres e crianças expandem as relações familiares para outros contextos, sem perder as relações que os compõem enquanto sujeitos (GODOI e PINA-CABRAL, 2014; PINACABRAL E SILVA, 2013).

Emerge desse contexto, portanto, uma pessoa que não era puramente individual, mas estava atrelada e constituída por diversas relações. Aqui, como procurarei demonstrar abaixo, atividades de conhecimento compartilhado eram ensinadas por intermédio da convivência. Em relação a esse cenário é que a passagem do tempo trazia transformações que evidenciavam e delineavam a escola como uma instituição presente na vida das famílias; o saber escolar surgia como uma alternativa que abria novas/outras possibilidades de trabalho.

\section{A infância e a quebra}

As mulheres que conhecemos em Codó, e com as quais pudemos conversar na aplicação dos questionários, tinham, em sua maioria, idades entre 40 e 60 anos (54\%). Nas suas trajetórias de vida, mais da metade delas quebrava coco há mais de três décadas, pois era comum que aprendessem o ofício ainda quando crianças - entre 7 e 12 anos. Nesses períodos, segundo nos contaram, viviam em povoados da zona rural do município ou de cidades próximas, onde suas famílias se dedicavam ao cultivo da roça, à quebra de coco e, em alguns casos, à criação de animais. Aprendiam o extrativismo frequentemente com mulheres mais velhas, suas mães ou suas avós (paternas e maternas), por intermédio da prática e da observação cotidiana.

A infância compartilhada por essas mulheres, portanto, incluía como parte constituinte dessa fase da vida as atividades de trabalho. Como apontam Ariès (1981), Donzelot (1980), Fonseca (2002), Almeida (2002), Tassinari (2009) e Pires (2007), as concepções de infância e adolescência se transformam de acordo com as sensibilidades compartilhadas por determinados grupos sociais, já que são contextuais e históricas. Nas narrativas das quebradeiras de coco, o trabalho aparecia como aspecto

9. Depoimento de Dona Efigênia, 55 anos, quebradeira de coco, separada, mãe e avó - em 04/08/2011. 10. Os nomes das interlocutoras utilizados nesse artigo são fictícios. É importante mencionar que a maioria das mulheres que se declarava solteira utilizava esse termo por não ter se casado formalmente. 
importante da rotina das crianças, de sua socialização e das relações com os adultos.

0 fato de as crianças fazerem atividades laborais não excluía, entretanto, o cuidado necessário com o desempenho das ações consideradas arriscadas, como a quebra de coco. Como diversas interlocutoras nos disseram, o início da quebra, na infância, foi acompanhado por mulheres mais velhas, que costumavam dar às meninas novas machados pouco afiados, para que não se ferissem. Também era frequente que as mulheres rachassem os cocos, dando às crianças apenas a função de extrair as amêndoas da sua parte interna. Dessa forma, se buscava diminuir o perigo da lida com os instrumentos de trabalho considerados perigosos.

Apesar das tentativas de diminuir os riscos, Socorro nos contou que quando era menina, sua mãe tinha constante receio de que ela se machucasse. Disse-nos ainda que as crianças tinham curiosidade e ao mesmo tempo familiaridade com a atividade da quebra de coco:

Ela [a mãe] tinha medo da gente se cortar. Ela citava, assim, o jeito da gente pegar no machado. Aí, de pequena a gente já via quebrando o coco, né? E a gente tinha aquela curiosidade de pegar assim, pra quebrar e pra ver como era. Ai ela brigava, às vezes, pra gente não pegar no machado, porque, às vezes meu pai amolava bem amolado e ela tinha medo da gente se cortar. (informação verbal ${ }^{11}$ ).

As cicatrizes causadas pelo uso do machado marcavam mãos, pernas e braços das mulheres. Algumas dessas cicatrizes surgiram ainda na infância, como o caso de Dona Nazaré, que começou a quebrar coco aos 7 anos de idade, quando "Não tinha força nem de rachar o coco. Ela [a mãe] rachava o coco pra mim. Aí lasquei esse dedo aqui uma vez" (informação verbal ${ }^{12}$ ). Receios e cuidados à parte, a quebra era uma atividade que era vista e acompanhada pelas crianças, já que atividades consideradas de adulto e de crianças não pertenciam a mundos separados ou opostos.

$\mathrm{Na}$ continuidade da conversa com Nazaré, ela se lembrou de que em torno de seus 10 anos de idade, além de quebrar coco, começou a pescar, para "buscar mistura para o arroz". De forma semelhante, Rita (55 anos, quebradeira de coco, casada, mãe e avó), na mesma época em que aprendeu a atividade extrativista, foi ensinada pela avó a fazer cestaria com fibras vegetais. Essas e outras narrativas mostram que, juntamente com o aprendizado da quebra, as crianças participavam de outras funções capazes de auxiliar no sustento doméstico e familiar.

Aprender a quebrar coco babaçu era algo que acontecia no cotidiano das crianças. As habilidades de rachar e partir o fruto eram parte de toda uma dinâmica de trabalho, que envolvia a entrada no mato, a relação com os vizinhos, a feitura do azeite e do carvão, a venda para os comerciantes. Era ainda um conhecimento que envolvia temporalidade, determinada rotina e gestão de recursos financeiros. A família de Dona Nazaré lidava com o coco "até na sexta-feira Santa", pois "era assim: a gente quebrava no dia para comer à noite. Só comia uma vez". Isso significava que sua família tinha uma renda muito restrita, que fazia com que não pudessem tirar folga nenhum dia - nem mesmo na sexta-feira santa, feriado religioso cele-

11. Depoimento de Dona Socorro, 29 anos, mãe, quebradeira e pequena empreendedora - em 26/07/2011.

12. Depoimento de Dona Nazaré, 54 anos, quebradeira de coco, solteira, mãe e avó - em 19/08/2011. 
brado em uma semana em que, na região, diversas atividades de trabalho eram suspensas. Durante a pesquisa de campo pudemos perceber que uma forma de dizer que uma quebradeira estava com "precisão”, ou seja, com problemas financeiros e dificuldades, era dizer que passava por um período em que "se quebra em um dia para comer em outro".

Esses aprendizados não eram, necessariamente, opostos ou exclusivos em relação ao ensino escolar. Dona Rita frequentou a escola na infância e acompanhava sua mãe nas idas para o mato. Ela recorda que era muito difícil, diante das características do contexto em que viviam, manter a frequência escolar, pois sua ajuda fazia falta no trabalho da família.

Aprendi assim, quando chegava da escola, que minha mãe tinha aquela preocupação de eu estudar Lá tinha uma escolinha e ai ela não queria me levar [para a quebra]. Não tinha um feriado... No dia que não tinha aula, eu chorava para ir com ela. "Minha filha não vá não!”. Eu dizia: “Eu quero ir para aprender" (informação verbal ${ }^{13}$ ).

Além de falar sobre as possibilidades de acesso à escola, Rita apontou um aspecto não tão evidente quando pensamos nas experiências ligadas ao coco babaçu: a curiosidade das crianças em aprender a atividade realizada pelas mulheres mais velhas. Suas lembranças a colocavam, como criança, para além de uma posição de passividade em relação às tarefas de trabalho, a apresentando como desejosa de participar da quebra ou de conhecê-la.

Na trajetória de outras quebradeiras de coco, como Dona Efigênia, a participação nas atividades realizadas pela família era o primordial da infância, pois as crianças contribuíam nas redes de cuidado e sustento familiar:

Lá em casa era assim: papai adoeceu. Aí minha mãe adoeceu também [...] Eu ia era trabalhar assim na roça dos outros, para poder comprar o quilo de arroz para comer. Chegava [em casa] estava mamãe sentada dormindo e eles sentados, eles três [pai, mãe e uma irmã com deficiência física]. Aí eu ia trabalhar pra poder comprar o que comer (informação verbal ${ }^{14}$ ).

Nessa mesma conversa, Dona Efigênia nos disse que não havia escola onde sua família vivia. Além dessa ausência, os relatos das quebradeiras de coco também apontam para o fato de que as escolas que eram ofertadas na zona rural eram muito precárias havia instituições sem professores, impossibilidade de deslocamento por ausência de transporte ou ainda frequência inconstante da oferta de aulas ${ }^{15}$.

13. Depoimento de Dona Rita - em 27/07/2011.

14. Depoimento de Dona Efigênia - em 04/08/2011.

15. A ausência da escola, ou a sua oferta insuficiente, refletiam nos índices de analfabetismo. A partir dos questionários com as quebradeiras de coco, soubemos que, no grupo das cem mulheres entrevistadas, 44\% sabiam ler e escrever - entre elas, 19 mulheres estudaram pelo menos ou até a $4^{\text {a }}$ série do ensino fundamental; 13 cursaram entre o $5^{\circ}$ e o $8^{\circ}$ ano do ensino fundamental; 5 tinham ensino médio incompleto e 7 o concluíram. No restante do percentual, 17\% das quebradeiras sabiam "pôr o nome", ou seja, assinar seu nome; e 39\% delas desconheciam qualquer forma de escrita ou leitura. Esses números expressam um alto indice de analfabetismo entre as quebradeiras de coco babaçu dado que corrobora com a taxa de analfabetismo da cidade de Codó, que no período da pesquisa chegava a 30\% da população adulta (IBGE, 2010). 
Nesses casos, a presença ou ausência na escola não era, necessariamente, uma questão central para as famílias das quebradeiras de coco. Por intermédio das suas falas, o que mais se destacava na experiência da infância era o aprendizado das atividades já realizadas por suas famílias - como a roça, a pesca, a quebra de coco, uma vez que eram essas as ocupações que permitiam a manutenção das casas e das comunidades onde viviam. As crianças eram percebidas como inseridas em redes de relação que compreendiam determinadas responsabilidades.

\section{A escola e as crianças}

Nas memórias das quebradeiras de coco, a infância acionava recordações sobre 0 trabalho, o aprendizado da atividade extrativista e as responsabilidades coletivas. 0 casamento e as experiências com a maternidade marcavam suas falas sobre os anos subsequentes, assim como a mudança do interior do município para a cidade. Como pretendo mostrar, esses acontecimentos estavam entrelaçados e compunham juntos argumentos sobre a escola, as novas gerações familiares e a continuidade, ou não, da quebra do coco.

Há, se pensarmos em um espectro mais amplo, um contexto que fala sobre transformações na configuração agrária do Maranhão nas últimas décadas e que incide sobre as vivências das quebradeiras de coco no que tange à mudança para a cidade. $\mathrm{Na}$ região em que se localiza Codó, desde a década de 1920, há um aumento da chegada de migrantes de diferentes estados nordestinos, impulsionados, entre outros motivos, pelo declínio do algodão no local de onde provinham e também pelas grandes secas. Segundo Antunes (2006), o processo migratório para o Vale do Itapecuru "tem seu pico entre as décadas de 1950 e 1960, se expandindo até 1970" (ANTUNES, 2006, p. 123), quando a região recebeu, especialmente, pessoas do Piauí e do Ceará.

Nesse contexto como fomos informadas por lideranças rurais vinculadas a um sindicato local - houve um processo de expropriação e de grilagem de terras que incidiu sobre os trabalhadores rurais pobres, muitas vezes os deslocando para a cidade. Em Codó, a partir da década de 1980, é possível perceber o incremento da densidade populacional no ambiente urbano ${ }^{16} .0$ campo passa a ser visto como local de manutenção de terra como reserva de valor e produção de gado onde, segundo Flávia Moura (2009, p. 28), a “[...] principal característica da estrutura agrícola é a predominância da grande propriedade fundiária - os latifúndios de mais de mil hectares ocupam quase 55\% da área total dos estabelecimentos".

Muitas das nossas interlocutoras estabeleceram casas no perímetro urbano nas décadas de 1980 e 1990. Contudo, ao mencionarem essas transformações, elas acrescentavam outras razões para a vinda e também para a permanência na cidade. Além do cenário da violência no campo, para falar da mobilidade entre a zona rural e a urbana, aludiam a acontecimentos como casamentos e as primeiras experiências com a maternidade. Após se tornarem mães (de criação ou de gestação), a escola apareceu entre as razões elencadas para a mudança:

[Viemos] Do [povoado] Saco pra cá, pra botar os filhos pra estudar, porque a escola não estava prestando. Assim, porque lá só tinha 
até a segunda série e tinha dia que a professora não ia. 0 povoado foi diminuindo lá era muito avançado, aí foi... E hoje em dia está daquele jeito, acabado. Ai todo mundo vinha [viver na cidade], aí a gente deu um jeito de comprar uma casinha na [rua] Mariano Saad e ai veio. (...) Estudar, estudar, porque nós viemos pra cá passar esse sofrimento todo que a gente passou (...) pra botar elas no colégio. Viemos pra cá se arrastando, arrastando mesmo, mas pra quê? "Pra botar vocês numa escola”, porque lá não tinha uma escola é uma escola que a professora vai um dia sim e outro não. Não é escola, não aprende. Aí se algum não quis [estudar] não quis... (informação verbal ${ }^{17}$ ).

Dona Rita é uma entre as diversas quebradeiras que afırmavam que a mudança para a cidade foi impulsionada, entre outros motivos, pela necessidade de acesso dos filhos à escola. A ausência da instituição escolar ou a oferta insuficiente do ensino eram argumentos para contar sobre o sacrifício desse movimento, que envolvia a compra ou construção de uma casa, normalmente em área pouco ocupada do perímetro urbano e em condições precárias de infraestrutura. Em sua fala, a diminuição do povoado - pela mobilidade de seus moradores - foi acionada, junto com a escola, para falar sobre o estabelecimento de uma moradia na cidade. Também aqui, no âmbito das mudanças e sacrifícios, como antes, na infância (no contexto do aprendizado e do trabalho), os planos são coletivos e as pessoas emergem não como entidades avulsas, mas como integrantes de unidades familiares, "fazendo parte de estratégias de sobrevivência e de luta que incluíam homens, mulheres, jovens, idosos e crianças" (PAULA ANDRADE, 2007, p. 447). Contudo, diferente das narrativas sobre a infância delas mesmas, as quebradeiras nos deixavam entender que, naquele momento, as crianças emergiam como algo que mobilizava a ação da família.

A mudança para a cidade, como indiquei no início do texto, era marcada pela continuidade de trabalho no campo. Diante da ausência de empregos no contexto urbano, da especialização das pessoas nos saberes relacionados à terra e das experiências laborais anteriores, as pessoas retornavam ao campo, semanal ou cotidianamente, para a quebra do coco babaçu e para colocar "linhas de roça”. "Colocar linhas de roça” era uma atividade desenvolvida na terra de algum conhecido, mas normalmente era feita em terra "alheia", em grandes propriedades, pela concessão mediante "acordo" com o dono das terras, quando se usava o espaço sem ônus financeiro ou se pagava ao proprietário em dinheiro ou em produção $0^{18}$. Dona Jesus nos falou sobre a continuidade das atividades no campo: "Aí quando eu cheguei aqui, continuei a mesma coisa, trabalhando no interior, trabalhando de roça, aí quebrando coco aí (...) eu continuo sempre no coco, nunca parei, de jeito nenhum" (informação verbal).

Essa nova configuração da rotina apresentou desafios do ponto de vista do cuidado das crianças e da manutenção da frequ-

17. Depoimento de Dona Rita - em 27/07/2011.

18. Como indica Moura (2009), essa forma de arrendamento da terra é vantajosa ao proprietário, que costuma se precaver de possíveis incômodos proibindo o arrendatário de plantar mais de dez linhas de roça, não deixando plantar mandioca que demora mais tempo para ser colhida e não alugando a terra por mais de cinco anos para o mesmo trabalhador, para não caracterizar posse do terreno. 
ência escolar. Algumas quebradeiras, nesse sentido, passaram a não mais quebrar coco durante a semana, pois não poderiam deixar as crianças sozinhas e nem levá-las ao mato por causa da escola - algo que faziam antes, quando os filhos não estavam em idade escolar. Algumas delas esperavam o turno da escola terminar na sexta-feira, quando pegavam os(as) filhos(as) e com eles(as) passavam o final de semana no interior, quebrando coco. Outras interrompiam a atividade extrativista durante o ano letivo e a realizavam apenas nas férias. Evidentemente, essa possibilidade existia quando o coco não era a única fonte de renda da família, ou seja, quando ela recebia, por exemplo, benefícios de programas sociais ou possuía outros trabalhos remunerados.

Nos relatos das quebradeiras de coco podemos perceber algumas transformações entre as experiências de seus filhos e filhas (netos e sobrinhos) e suas próprias vivências em torno da escola. Antes, na infância das quebradeiras, havia povoados sem instituição escolar, a vida era percebida como mais difícil, as situações como de maior "precisão" e a escola não aparecia como uma questão central para a reprodução da família. Diferentemente, em 2011, a vida na cidade, os programas sociais que exigiam vínculo das crianças com a educação formal, o aumento do acesso à escola no Brasil, entre outros fatores, permitiam que esta se apresentasse mais constantemente nas experiências das pessoas. Como indicavam as quebradeiras de coco durante nossa pesquisa, a escola era vista como algo necessário para expandir as oportunidades de trabalho da nova geração: elas compreendiam, como ilustro com a fala de Dona Generosa, que não saber ler e escrever restringia as ocupações laborais:
É quebrar coco, a profissão que eu tenho só é essa [...] É minha profissão, quebrar coco. Aí a pessoa não tem outro emprego, tem que quebrar coco mesmo. 0 emprego que aprendeu foi esse. Eu não sei ler, como posso trabalhar num lugar? E hoje em dia, quem não sabe ler, nem varrer rua não varre. Porque tem que assinar [escrever o próprio nome] (informação verbal ${ }^{19}$ ).

Perceber a escola como alternativa nascia da percepção de que a quebra de coco era uma atividade árdua, de caráter "pesado" e "cansativo". Essas características tinham a ver com o deslocamento para o mato e os perigos que esse deslocamento apresentava (como a potencial violência do isolamento, a presença de animais como as cobras); o peso dos sacos de coco carregados ao fim do turno de trabalho; a lida com instrumentos cortantes; as dores e doenças diversas que estavam relacionadas à posição corporal na quebra e à alimentação precária. Além disso, era uma atividade considerada mal remunerada. Entretanto, a aposta na educação formal como a abertura de um leque de possibilidades de trabalho e emprego, não era algo unívoco ou exclusivo, que sintetizava os investimentos das mulheres em relação aos seus/suas filhos(as) e netos(as). Como procurarei demonstrar abaixo, havia, como em outros contextos de pesquisa (TASSINARI, 2009; BRANDÃO, 1983), um olhar crítico sobre a escola.

\section{Apostas e imponderáveis}

Uma leitura rápida em torno das considerações das quebradeiras de coco sobre a escola - nas quais esta figura como elemento motivador de mudanças e escolhas -, entretanto, não dá conta da forma como 
as nossas interlocutoras pensavam as relações entre o conhecimento escolar e o saber tradicional da quebra. Isso se mostra evidente no fato de que muitas delas matriculavam seus filhos na escola, mas também lhes ensinavam a quebra de coco. Transcrevo, abaixo, uma passagem da entrevista com Dona Delfina, quando ela fala sobre seus filhos e filhas, sobre a educação formal e o babaçu:

Pesquisadora: Seus filhos, eles estudaram? Eles foram pra escola?

Delfina: Eles quebraram coco enquanto eram pequenos, aí, depois quando nós viemos aqui pro Codó, do interior, eu botei pra estudar. Quando nós chegamos aqui no Codó eles estudaram, mas eles iam pro mato mais eu [...] No dia que eles não iam pro colégio nós íamos pro mato e foi assim até que todo mundo pegou o seu rumo (informação verbal ${ }^{20}$ ).

Ensinar aquilo que se sabia, do ponto de vista do trabalho, era percebido, no contexto da pesquisa, como responsabilidade dos pais e como característica de um boa educação. Era, portanto, importante ensinar as crianças a quebrar coco - algo que não figurava como um incentivo ao trabalho infantil ou ao abandono escolar, como uma visão apressada e sustentada em outras sensibilidades poderia sugerir.

Essa dupla aposta - na quebra e na escola - coloca (pelo menos) duas questões: a primeira sobre a compreensão da instituição escolar; e a segunda sobre a passagem do tempo, especialmente sobre as concepções locais daquilo que chamamos de futuro. A escola, enquanto instrumento central de ensino e aprendizagem na sociedade oci- dental, é vista criticamente por determinada literatura no âmbito das ciências sociais. Esses autores e autoras colocam em pauta a necessidade de analisar a escola levando em consideração variáveis como raça, etnia e classe. 0 sociólogo Daniel Thin (2006), por exemplo, demonstra como a instituição escolar não é neutra, mas carrega valores (evidentes na organização do tempo e do currículo da escola, na forma como se estabelece a relação entre professor/aluno/ família) relacionados ao modo de vida das classes médias.

No âmbito da antropologia, pesquisas em contextos de campesinato, em comunidades tradicionais e sociedades indígenas têm ponderado e limitado o poder do discurso sobre a escola como alternativa "salvadora" ou "modernizadora" desses grupos. Já na década de 1980, Carlos Rodrigues Brandão (1983) mostrava que, para os trabalhadores rurais, a educação formal era vista como diferente ou mesmo contrária ao saber do mundo rural. Nesse sentido, a escola servia apenas para adquirir um conhecimento capaz de dar conta de um conjunto restrito de coisas, relacionadas, naquele contexto, ao mundo "moderno".

Antonella Tassinari (2009), nos estudos que tem realizado sobre infância e educação, problematiza o ingresso da escola em terras indígenas, a partir do aparente paradoxo ente os pedidos para a sua implementação, por parte dos próprios grupos, e o valor adstrito dado ao conhecimento transmitido por essa instituição. Há, nessas situações, segundo argumentação da autora, não apenas uma relação entre duas formas de conhecimento, mas duas maneiras de perceber a infância: a dos grupos não

20. Depoimento de Delfina, 51 anos, casada, pensionista - em 18/08/2011. 
indígenas, que traz uma amálgama entre aluno(a) e criança, de forma que um não é concebido sem o outro, o que nos leva a compreender a criança como um receptáculo do conhecimento; e a concepção indígena de infância, marcada pela importância da opinião das crianças, pelo papel de mediação que fazem entre diferentes pessoas e seres sobrenaturais, pela ausência de uma oposição excludente entre mundo das crianças e mundo dos adultos.

Essa literatura nos mostra que a escola - sua organização curricular, espacial e temporal - carrega valores de determinados grupos étnicos e classes sociais. Os autores discorrem, nesse sentido, sobre desencontros que acontecem entre concepções de infância, pessoa e educação nas relações entre a escola e contextos específicos. A percepção das mulheres que acompanhamos também limitava a eficácia da escola. Muito embora a vissem como transmissora de um conhecimento que se tornou necessário às novas gerações e que poderia ampliar suas possibilidades de trabalho e renda, elas não eliminariam a quebra de coco, que era percebida como atividade conhecida e garantidora da manutenção da vida. Ou seja, a despeito dos planos relativos à continuidade (ou não) no extrativismo do babaçu, as quebradeiras concordavam que essa atividade era uma espécie de segurança para o sustento.

Essa compreensão nos remete à temporalidade - seja ela do âmbito da organização do cotidiano, seja dos planos feitos para o futuro. Quando as quebradeiras de coco babaçu de Codó falavam sobre o ingresso de seus filhos na escola, mostravam que a frequência escolar alterava a rotina da atividade extrativista. Esta, como vimos, era realizada por intermédio do deslocamento das mulheres para a zona rural do muni- cípio. Em momentos de maior necessidade financeira, esse deslocamento era diário. 0 retorno financeiro desse trabalho também era diário, pois se recebia no fim do dia, na venda do coco.

A escola, entretanto, não trazia retorno imediato no que tange aos recursos financeiros, pois, como vimos, assentava suas premissas sobre uma noção de infância distanciada do mundo do trabalho e do sustento. Colocar as crianças na escola e reconhecer que ela pode trazer novas oportunidades de trabalho é deslocar qualquer retorno para um tempo vindouro. Era uma aposta sem garantias, pois o que viria ainda era algo indeterminado.

Nesses deslocamentos temporais, a atividade da quebra de coco - realizada com maior/menor intensidade - sempre esteve presente na vida das mulheres. Essa constância é um elemento fundamental para compreender seu aspecto de segurança. Tal como buscavam reduzir os riscos físicos sobre os corpos das crianças quando lhes ensinavam a utilizar os instrumentos da quebra; a restringir as ameaças da mata com os pedidos de proteção; e a diminuir o impacto do ambiente sobre o corpo, colocando roupas consideradas apropriadas. Ensinar a atividade extrativista era uma forma de anteciparse sobre o tempo, uma tentativa de dominar o medo diante daquilo que foge ao controle. Sendo impossível antever o que aconteceria nos anos subsequentes, a escola participava de um tempo ainda incerto. Era importante saber que nos momentos de maior "precisão”, que poderiam surgir, suas filhas e seus filhos saberiam como quebrar coco.

Hirokazu Miyasaki, em The Method of Hope (2004) sugere que a esperança, enquanto otimismo, é uma forma de pensamento crítico que nos permite ver aspectos de resistência e criatividade diante de ce- 
nários e contextos políticos marcados pelo conservadorismo e pela desigualdade. Para o autor, a esperança é uma metodologia, uma forma de construir conhecimento sobre o mundo. A partir de suas considerações podemos sugerir que entre os saberes escolares e os tradicionais da quebra de coco, as mulheres de Codó teciam apostas baseadas no conhecimento que possuíam sobre a vida que as cercava. Enquanto esperança, não estou sugerindo que as quebradeiras "esperavam" ou significavam o futuro distante do extrativismo como superior, ou mesmo melhor que o da quebra de coco. 0 que, me parece, elas esperavam e faziam (continuamente diante das mudanças e apostas que realizavam), era traçar estratégias para lidar com o que viria.

\section{Considerações Finais}

Durante a pesquisa de campo que fizemos com as quebradeiras de coco babaçu em Codó, chamaram nossa atenção diversas falas sobre a escola. Neste artigo, minha intenção foi pensar algumas dessas considerações em relação à atividade extrativista da quebra de coco, tentando compreender como a educação formal se tornou uma questão na vida dessas mulheres. A quebra de coco é um saber tradicional que, no contexto pesquisado, estava vinculado às mulheres e à transmissão geracional de conhecimento. Ele concernia não apenas ao ato de quebrar o fruto, mas englobava o reconhecimento do ambiente da mata, da situação da palmeira, das redes de venda e produção dos seus derivados. Estava conectado a uma concepção de família e infância em que o sustento e o trabalho eram responsabilidades coletivas que engajavam, também, as crianças.

A escola, por sua vez, apresentava um conjunto de conhecimentos distantes do trabalho na quebra de coco. Entretanto, eles eram reconhecidos por nossas interlocutoras como importantes no cenário urbano onde moravam e apareciam, inclusive, como uma das razões para justificar a mudança do contexto rural para a cidade. No momento em que viviam, a escola - pensada a partir da sua função de ensinar a ler e escrever - trazia um saber sem o qual as oportunidades de trabalho se reduziam. Dado o caráter "pesado" da atividade extrativista, as quebradeiras desejavam que seus filhos e filhas tivessem a possibilidade de ter outras profissões.

Embora o desejo de que a escola ampliasse oportunidades de trabalho, o futuro era formado por imponderáveis que extrapolavam as possibilidades de controle. A contribuição da família, nesse cenário, era ensinar uma atividade que, historicamente, era garantia de acesso ao sustento - a quebra do coco babaçu. Não desvincular totalmente as crianças dos saberes do mundo rural era uma forma de analisar criticamente o poder da escola inserida num contexto de desigualdades sociais evidentes e de imprevisibilidade das condições de vida. Era, portanto, uma forma de perceber criticamente a realidade e a passagem do tempo.

Como saberes, a escola e a quebra de coco eram maneiras de olhar, conceber ou conhecer o mundo. Nosso exercício de pesquisa com as quebradeiras de coco babaçu de Codó, como demonstrei marcado por assimetrias e aproximações em relação ao contexto da quebra -, pode ser, nesse sentido, pensado paralelamente a esses saberes, como uma forma ou uma perspectiva a partir da qual buscamos compreender determinadas situações sociais. Essas situações, em alguma medida, eram familiares a nós, membros da equipe. Por um lado, porque as quebradeiras de coco faziam parte do cená- 
rio da cidade na qual vivíamos - as víamos pelas ruas, à espera do transporte, carregando sacos de coco. Por outro, porque o mundo rural não era externo às experiências de vida de vários de nós e de nossas famílias que também estavam, naquele momento, participando do ingresso das novas gerações no ensino superior.

Entretanto, minha intenção, ao mostrar essas aproximações, não é sugerir que conhecíamos, previamente, a maneira como as quebradeiras de coco viviam - já que é fundamental para a pesquisa desconstruir determinados pontos de vista. Antes, é mostrar que as considerações apresentadas neste texto são fruto de uma (e apenas uma) perspectiva sobre as relações estabelecidas entre a quebra de coco e a escola. Uma forma de olhar matizada por esses conhecimentos prévios e relacionada às nossas próprias trajetórias (HARAWAY, 1995), assim como pelos nossos interesses de pesquisa. A nossa perspectiva, a partir da pesquisa, buscou dar conta da forma aberta e crítica de conceber o futuro das quebradeiras - com esperança.

\section{Referências}

AHLERT, M. A "precisão" e o "luxo": usos do benefício do Programa Bolsa Família entre as quebradeiras de coco de Codó (Maranhão). In: Política e Trabalho - Revista de Ciências Sociais, n. 38, p. 69-86, abril de 2013a.

Cidade relicário: uma etnografia sobre terecô, precisão e Encantaria em Codó (MA). 2013. 282f. Tese (Doutorado em Antropologia Social), Brasília: Universidade de Brasília. 2013b.

ALMEIDA, A. W. B. (Org.). Terras de preto no Maranhão: quebrando o mito do isolamento. São Luís: ECN; SMDH; PVN, 2002.
ALMEIDA, P. C. S. Gravidez na adolescência em grupos populares urbanos: concepções de idade e maternidade. In: ALMEIDA, Heloisa et al. (Orgs.). Gênero em matizes. Bragança Paulista: Editora da Universidade de São Francisco, p. 177-212, 2002.

ANTUNES, M. de 0. As guardiãs da floresta do babaçu e o tortuoso caminho do empoderamento. In: WOORTMANN, E. F.; MENASCHE, R.; HEREDIA, B. M. A. (Orgs.). Margarida Alves: Coletânea sobre estudos rurais e gênero. Brasília: MDA; IICA, p. 123-149, 2006.

ARIÈS, P. A história social da criança e da família. Rio de Janeiro: Zahar, 1981.

BARBOSA, V. 0. A caminho dos babaçuais: gênero e imaginário no cotidiano de trabalhadores rurais no Maranhão. In: WOORTMANN, E. F.; MENASCHE, R.; HEREDIA, B. M. A. (Orgs.). Margarida Alves: Coletânea sobre estudos rurais e gênero. Brasília: MDA; IICA, p. 35-64, 2006.

. Na terra das Palmeiras: gênero, trabalho e identidades no universo de quebradeiras de coco babaçu no Maranhão. 2007. 150f. (Dissertação de Mestrado). Programa Multidisciplinar de Pós-Graduação em Estudos Étnicos e Africanos, Salvador: Universidade Federal da Bahia, 2007.

BRANDÃO, C. R. Casa de escola: cultura camponesa e educação rural. Campinas, São Paulo: Papirus, 1983.

CALÁVIA-SAEZ, 0. Esse obscuro objeto da pesquisa. Ilha de Santa Catarina: Edição do autor, 2013.

CALDEIRA, T. A política dos outros: o cotidiano dos moradores da periferia e o que pensam do poder e dos poderosos. São Paulo: Brasiliense, 1984.

Mujeres, cotidianidad y politica. In: JELIN, E. (comp.) Ciudadania e identidad: Las mujeres en los movimientos sociales latino-americanos. Ginebra: Instituto deInvestigaciones de las Naciones Unidas para el Desarrollo Social, p. 75-125, 1987.

CANDIDO, A. Os parceiros do Rio Bonito. Estudo sobre o caipira paulista e a transformação dos seus meios de vida. Rio de Janeiro: Ouro sobre Azul, 2010. 
DONZELOT, J. A polícia das famílias. Rio de Janeiro: Graal, 1980.

DUARTE, L. F. D. Da vida nervosa das classes trabalhadoras urbanas. Rio de Janeiro: CNPq; Zahar, 1986.

FONSECA, C. Quando cada caso não é um caso. In: Revista Brasileira de Educação, n.10, p. 5878, 1999.

. Caminhos da adoção. São Paulo: Cortez, 1995.

Família, fofoca e honra: etnografia de relações de gênero e violência em grupos populares. Porto Alegre: Editora da UFRGS, 2004.

GODOI, E. P. 0 trabalho da memória: cotidiano e história no sertão do Piaui. Campinas: Editora da UNICAMP, 1999.

Reciprocidade e circulação de crianças entre camponeses do sertão. In: GODOI, E. P.; MENEZES, M. A.; MARIN, R. A. (Orgs.). Diversidade do campesinato: expressões e categorias - estratégias de reprodução social. São Paulo: Editora UNESP, p. 289-302, 2009.

Mobilidades, encantamentos e pertença: o mundo ainda está rogando porque ainda não acabou. In: Revista de Antropologia, São Paulo, USP, v. 57, n. 2, p. 143-170, 2014.

GODOI, E. P.; PINA-CABRAL, J. Apresentação: vicinalidades e casas partíveis. In: Revista de Antropologia, São Paulo, USP, v. 57, n. 2, p. 11-21, 2014.

HARAWAY, D. Saberes localizados: a questão da ciência para o feminismo e o privilégio da perspectiva parcial. Cadernos Pagu, n. 5, p. 7-41, 1995.

HEREDIA, B. M. A. de. A morada da vida: trabalho familiar de pequenos produtores do Nordeste do Brasil. Rio de Janeiro: Paz e Terra, 1979.

MENEZES, M. A.. Migrações: uma experiência histórica do campesinato do Nordeste. In: GODOI, E. P.; MENEZES, M. A.; MARIN, R. A. (Orgs.). Diversidade do campesinato: expressões e categorias - estratégias de reprodução social. São Paulo: Editora da UNESP, p. 269-287, 2009.
MINTZ, S. Comida e Antropologia. Uma breve revisão. In: Revista Brasileira de Ciências Sociais, v. 16, n. 47, p. 31-41, outubro 2001.

MIYAZAKI, H. The method of hope: anthropology, philosophy and Fijian knowledge. Stanford: Stanford University Press, 2004.

MOURA, F. de A. Escravos da precisão: economia familiar e estratégias de sobrevivência de trabalhadores rurais em Codó - MA. São Luís: EDUFMA, 2009.

PAULA ANDRADE, M. Conflitos agrários e memória de mulheres camponesas. Estudos Feministas, Florianópolis, v.2, n. 15, p. 445-451, maio/ago. 2007.

PEIRANO, M. Etnografia não é método. In: Revista Horizontes Antropológicos. ano 20, n. 42, p. 377391, jul./dez. 2014.

PINA-CABRAL, J.; SILVA, V. A. Gente livre: consideração e pessoa no Baixo Sul da Bahia. São Paulo: Terceiro Nome, 2013.

PIRES, F. Ser adulta e pesquisar crianças: explorando possibilidades metodológicas na pesquisa antropológica. In: Revista de Antropologia, v. 50, p. 225-270, 2007.

SARTI, C. A. A familia como espelho: um estudo sobre a moral dos pobres. Campinas: Autores Associados, 1996.

STRATHERN, M. 0 gênero da dádiva: problemas com as mulheres e problemas com a sociedade na Melanésia. Campinas: Editora da UNICAMP, 2006.

TASSINARI, A. Múltiplas infâncias: o que a criança indígena pode ensinar para quem já foi à escola ou a sociedade contra a escola. In: Anais do 33 Encontro Anual da Anpocs. Caxambu, 26 a 30 de outubro de 2009.

THIN, D. Para uma análise das relações entre famílias populares e escola: confrontação entre lógicas socializadoras. In: Revista Brasileira de Educação, v. 11 n. 32, maio/ago. 2006.

TOREN, C. A matéria da imaginação: o que podemos aprender com as ideias das crianças fijianas sobre suas vidas como adultos. In: Revista Horizontes Antropológicos, ano 16, n. 34, p. 19-48, julho/dezembro 2010. 
ZALUAR, A. A máquina e a revolta: as organizações populares e o significado da pobreza. São Paulo: Brasiliense, 1985.

WAGNER, R. A invenção da Cultura. São Paulo: Cosac Naify, 2010.

WOORTMANN, E. F. Herdeiros, parentes e compadres: Colonos do Sul e Sitiantes do Nordeste. São Paulo; Brasília: HUCITEC; EdUnb, 1995.

WOORTMANN, K. Migração, família e campesinato. In: WELCH, C. et al. (Org.). Camponeses Brasileiros: leituras e interpretações clássicas. São Paulo; Brasília: MDA, UNESP; NEAD, p. 217-241, 2009. 


\section{RESUMO}

Este artigo discorre sobre questões relativas à escola em um grupo de quebradeiras de coco babaçu da cidade de Codó (Maranhão). Analisa suas narrativas sobre infância destacando a presença feminina e familiar no aprendizado da atividade da quebra de coco em contextos rurais. Posteriormente, pensa a presença da instituição escolar nas suas narrativas sobre os filhos e netos. Por fim, trata das sutilezas e ambiguidades que estão presentes nas articulações entre ensinar a quebra de coco e incentivar a presença, das novas gerações, na escola.

\section{PALAVRAS-CHAVE}

Família. Quebradeiras de coco. Escola.

\section{ABSTRACT}

This article discusses questions regarding the relationship between school and babaçu coconut breakers group in Codó city (Maranhão). It analyzes their narratives about childhood, highlighting the female and familiar presences in the babaçu coconut breaking activity on a rural context. Subsequently, thinks about the educational institution presence on their narratives concerning sons and grandsons. Finally, deals with the subtleties and ambiguities present in the articulations of teaching babaçu coconut breaking and stimulating the attendance, of new generations, at school.

\section{KEYWORDS}

Family. Babaçu coconut breakers. School. 